\section{Economic Analysis of an Isolated Product Obtained from Muscadine Grape Pomace}

\author{
Jorge A. Cardona ${ }^{1,3}$, Allen F. Wysocki ${ }^{2}$, and Stephen T. Talcott ${ }^{3,4}$
}

AdDITIONAL INDEX WORDs. Vitis rotundifolia, by-products, polyphenolics, profitability

SUMMARY. The grape (Vitis vinifera) industry has long been a leader in the utilization of edible by-products to increase the revenue of the industry with products such as grape seed extract, dried pomace, and pigment extracts. However, the muscadine grape (Vitis rotundifolia) industry in the southeastern United States has lagged in the development of secondary products from wine and juice manufacture due to economic and processing limitations associated with this grape. Processing of pomaces rich in polyphenolics, such as muscadine grapes, can lead to an increase in economic value per ton of fruit and the decrease of waste material generated. Therefore, the profitability of two drying technologies (spray drying and vacuum concentration) was assessed as means to extract and concentrate polyphenolics from muscadine grape pomace. An economic analysis was conducted based on break-even point analysis, sensitivity analysis, and return on investment estimation. Assumptions were required to complete the analysis. Using initial production conditions $(124 \mathrm{~kg}$ of extract at $\$ 140 / \mathrm{kg}$, and $11,309 \mathrm{~kg}$ of dried skins at $\$ 3.00 / \mathrm{kg}$ ), the profit generated from spray drying was higher than vacuum concentration. In addition, return of investment was $10 \%$ higher in spray drying (22.2\%) compared with vacuum concentration (12.3\%), which barely covered the net present value of the operation. Although spray drying proved to be a less expensive technology (with the actual characteristics and proper assumptions), the vacuum evaporator used for this situation had three times the capacity of the spray dryer, thus only vacuum concentration would support a potential growth in extract production if the volume processed was to be increased significantly. Sensitivity analysis illustrated that both technologies obtained positive results with initial production conditions with a $40 \%$ increase in production and prices. This study also illustrated various assumptions that could be changed to recalculate and readjust investment and costs of any processor.

$\mathrm{F}$ unctional food and beverage consumption is growing due to major consumer trends toward health consciousness. As a result of consumer awareness, natural products such as food colorants and antioxidants have gained substantial attention in the market (Milo, 2005). Such growing demand for natural products has created an opportunity to substitute synthetic antioxidants by natural compounds. Among the traditional antioxidants used are butylated hydroxyanisole (BHA) and butylated hydroxytoluene (BHT), which have been associated with potential toxicity. Furthermore, the manufacturing costs of these compounds are more expensive than natural antioxidants extracted from

${ }^{1}$ Department of Food Science and Human Nutrition, University of Florida, Gainesville, FL 32611

${ }^{2}$ Department of Food and Resource Economics, University of Florida, Gainesville, FL 32611-0240

${ }^{3}$ Department of Nutrition and Food Science, Texas A\&M University, College Station, TX 77843-2254

${ }^{4}$ Corresponding author. E-mail: stalcott@tamu.edu. fruit and vegetable sources (Moure et al., 2001). Natural antioxidants such as vitamin $\mathrm{C}$, tocopherols, polyphenolics, and organic acids can be found in fruit, vegetables, spices, and herbs (Meyer et al., 2002). Moreover, polyphenolics can be widely found in pomace or wastes of numerous fruit and vegetables after processing (Bonilla et al., 1999; Klopotek et al., 2005; Monagas et al., 2006; Pastrana-Bonilla et al., 2003; Visioli et al., 1999), and these sources represent an inexpensive material to potentially create food ingredients. As a result, the interest in natural antioxidants and the occurrence of these compounds in by-products has driven fruit and vegetable processors to attempt to extract polyphenolics from their wastes and increase the profitability of their operations.

Muscadine grape is an important native fruit crop to the southeastern U.S. and was cultivated and used by people in these regions before European colonization (Poling, 1996). Grown for its ability to withstand hot and humid summers and warm winters, this grape has a natural adaptation against a condition called pierce's disease caused by a bacterium (Xyllella fastidiosa). It is used commercially to manufacture wine, juice, and preserves (Olien and Hegwood, 1990; Ruel and Walker, 2006). The grape is characterized by a thick skin that retains appreciable amounts of antioxidant polyphenolics. Because $40 \%$ of the fruit is skin (PastranaBonilla et al., 2003), only about half of the fruit is used in conventional products such as juice and wine. Consequently, muscadine grape pomace represents an important source of polyphenolics (Morris and Brady, 2004; Pastrana-Bonilla et al., 2003) that has not been used and could be an important source to generate food ingredients. In Georgia alone, around 1.5 million pounds of dry muscadine skins are produced yearly and could be transformed into very profitable products (Phillips, 2006). Research has focused on converting muscadine grape and blueberry (Vaccinium corymbosum) pomace into nutraceutical products that could be sold for as much as $\$ 100 / \mathrm{lb}$ (Phillips, 2006). In addition, processing of pomaces not only can lead to an increase in economic value per ton of fruit, but also to decrease waste materials (Ector, 2001). Pigments could be extracted from the skins and be used as food ingredients. These compounds could then contribute to the overall color and increase phytochemical content of food products (Morris and Brady, 2004).

Many studies have focused on the economic evaluation of fruit production and harvesting, (Saftley et al., 2004, 2006), but the economic impact assessed at the processing level

\begin{tabular}{llll}
\hline $\begin{array}{l}\text { Units } \\
\begin{array}{l}\text { To convert U.S. to SI, } \\
\text { multiply by }\end{array}\end{array}$ & U.S. unit & SI unit & $\begin{array}{l}\text { To convert SI to U.S., } \\
\text { multiply by }\end{array}$ \\
\hline 0.4536 & $\mathrm{lb}$ & $\mathrm{kg}$ & 2.2046 \\
1 & $\mathrm{ppm}$ & $\mathrm{mg} \cdot \mathrm{kg}^{-1}$ & 1 \\
0.9072 & ton(s) & $\mathrm{Mg}$ & 1.1023
\end{tabular}


has yet to be analyzed specifically for muscadine grapes. Therefore, the aim of this study was to analyze the profitability of two technologies (spray drying and vacuum concentration) to extract and concentrate polyphenolics from muscadine grape pomace as an incremental operation to a typical grape juice production facility.

\section{Materials and methods}

Data collection. Primary data regarding the nature of the muscadine grape industry and its operations was collected by interviewing a muscadine grape processor of southern Georgia. Other primary information regarding equipment specification, capacity, and pricing was collected by interviewing companies responsible for selling used equipment for food industries. Assumptions used in this work were drawn from interview comments and educated estimations.

ECONOMic Assumptions. For the analyses, it was assumed that land and some equipment needed for the additional operation was already owned by a typical muscadine grape juice processor and was not included in the capital investment. The extra cost of equipment not owned by the processor was quoted by equipment vendors (Table 1 ). A building construction cost of $\$ 70,000$ was assumed to be paid in 10 years through a bank loan (Table 2). Pomace from 90 tons of muscadine grapes was assumed to be allocated to this by-product operation and used as the starting material for polyphenolic extraction during the 2 months of a typical muscadine grape harvesting season. Because muscadine grape pomace is a by-product of the same juice operation, it was not included as a cost in the analysis. Input prices and labor needs were obtained from muscadine juice processors. Two final products can be generated from this operation, a polyphenolic extract (valued at $\$ 140 / \mathrm{kg}$ ) and dried skins (valued at $\$ 3.00 / \mathrm{kg}$ ) after polyphenolic extraction. Four employees were needed for this additional operation and were assumed to be paid $\$ 8 / \mathrm{h}$ working $4 \mathrm{~h}$ per day on this process. Labor time was mostly assigned to the extract manufacturing $(70 \%)$, while $30 \%$ was spent on skin drying. No hauling or marketing costs were taken into account in this analysis. Proposed prices for yeast and

Table 1. General information of drying equipment considered for an additional operation to obtain extract and dry residue skins from muscadine grape pomace.

\begin{tabular}{lccc}
\hline Equipment & $\begin{array}{c}\text { Estimated } \\
\text { cost }(\$)\end{array}$ & $\begin{array}{c}\text { Estimated capacity } \\
\left(\mathbf{k g} \cdot \mathbf{h}^{-1}\right)^{\mathrm{z}}\end{array}$ & $\begin{array}{c}\text { Estimated electrical } \\
\text { demand }(\mathbf{k W})\end{array}$ \\
\hline Vacuum dryer & 150,000 & 300 & 39.0 \\
Spray dryer & 84,000 & 100 & 25.0 \\
Residue dryer & 100,000 & 250 & 16.0 \\
\hline
\end{tabular}

${ }^{\mathrm{z}} \mathrm{l} \mathrm{kg}=2.2046 \mathrm{lb}$.

Table 2. Loan payment plan to finance the construction of a new building for a process to obtain extract and dry skin from muscadine grape pomace at a fixed rate of $7.5 \%$.

\begin{tabular}{lccccc}
\hline $\begin{array}{l}\text { Initial debt } \\
\text { [ID (\$)] }\end{array}$ & $\begin{array}{c}\text { Rate }^{\mathrm{z}} \\
(\%)\end{array}$ & $\begin{array}{c}\text { Payment }^{\mathrm{y}} \\
(\mathbf{\$})\end{array}$ & $\begin{array}{c}\text { Interest } \\
(\mathbf{\$})\end{array}$ & $\begin{array}{c}\text { Amortization } \\
{[\mathbf{A}(\mathbf{})]}\end{array}$ & $\begin{array}{c}\text { Debt }^{\mathrm{x}} \\
\text { [ID - A (\$)] }\end{array}$ \\
\hline 70,000 & 7.50 & 7,525 & 998 & 6,528 & 63,473 \\
63,473 & 7.50 & 7,525 & 893 & 6,633 & 56,840 \\
56,840 & 7.50 & 7,525 & 788 & 6,738 & 50,103 \\
50,103 & 7.50 & 7,525 & 683 & 6,843 & 43,260 \\
43,260 & 7.50 & 7,525 & 578 & 6,948 & 36,313 \\
36,313 & 7.50 & 7,525 & 473 & 7,053 & 29,260 \\
29,260 & 7.50 & 7,525 & 368 & 7,158 & 22,103 \\
22,103 & 7.50 & 7,525 & 263 & 7,263 & 14,840 \\
14,840 & 7.50 & 7,525 & 158 & 7,368 & 7,473 \\
7,473 & 7.50 & 7,525 & 53 & 7,473 & - \\
\hline
\end{tabular}

${ }^{z}$ Rate estimated from a normal bank for a fixed rate loan.

yayment is constituted by amortization and interest.

${ }^{x}$ Debt is the result of subtracting annual amortization from previous period debt.

diatomaceous earth required in the fermentation and clarification were $\$ 21.8 / \mathrm{kg}$ and $\$ 3.20 / \mathrm{kg}$, respectively. The ratios planned to be used for yeast and diatomaceous earth were 0.125 and $0.5 \mathrm{~kg}$ per $50 \mathrm{~kg}$ of extract, respectively. For the cash flow calculations, $20 \%$ was used as a tax rate and $1 \%$ of the total revenue was assigned for other activities such as cleaning and maintenance needed in the operation. Installation fees for dryers and filters were assumed to be $40 \%$ and $70 \%$ of the total cost of the machinery, respectively. Operation time (for drying) was calculated based on the volume produced per day, and for electrical calculations, extra time (1 h) was added for basic maintenance and warming up of equipment.

Linear depreciation was used for analysis and time depended on the nature of the asset. Construction was depreciated in 20 years, equipment was depreciated in 5 years, and other materials such as pumps and bins were depreciated over 10 years. The final consumer for the polyphenolic extract was supposed to be a processor that would use the product as a food ingredient, while the dried skins were intended to be sold as animal feed.
DESCRIPTION OF THE OPERATION. The intended operation was assumed to be an extension of a juice process facility illustrated in Fig. 1. After grapes have been pressed for juice manufacture, the waste was collected and mixed with hot water $(1: 2)$ to allow soluble compounds to migrate to water, creating a liquid extract. A pressing procedure following the initial extraction was necessary to remove skins to initiate a controlled fermentation. Furthermore, the residual skins could be dried and sold as animal feed. Next, sugars, which have migrated into the liquid extract, were removed to facilitate further processing. Sugars were removed by aerobic fermentation followed by a series of filtrations that allowed separation of insoluble compounds. Lastly, a drying protocol was necessary to obtain an isolated product rich in polyphenolics. Two concentration protocols were considered for the process: spray drying and vacuum concentration.

From a previous investigation (Cardona, 2007), a muscadine extract was found to contain about 1600 $\mathrm{mg} \cdot \mathrm{kg}^{-1}$ as gallic acid equivalents of total polyphenolics. This value was 
used as the initial content (before concentration) for the product used to create a dry or concentrated extract. All relevant calculations were based on this proportion. From 90 tons of grapes, $40 \%$ represented skins (Pastrana-Bonilla et al., 2003) that were directly intended for the secondary process to obtain the polyphenolic extract. This resulted in a season-long production of $36,000 \mathrm{~kg}$ of fresh skins that were intended to be mixed with hot water (2:1 ratio) for a production of $72,000 \mathrm{~kg}$ of liquid extract and $36,000 \mathrm{~kg}$ of residual skins. Based on a liquid extract concentration of $1600 \mathrm{mg} \cdot \mathrm{kg}^{-1}$ total polyphenolics, and assuming $5 \%$ moisture on final dried extract, the process would yield $124 \mathrm{~kg}$ in a single harvest season. From the remaining skins after fermentation, $30 \%$ was considered solids (Phillips, 2006) and was proposed to be sold as animal feed as part of the by-product operation, which would also contain $5 \%$ residual moisture. A total of $11,309 \mathrm{~kg}$ of dried residual skins after polyphenolic extraction could be produced in a single season.

ECONOMiC ANALYsis. An economic analysis was conducted based on profitability, sensitivity, and economic return of two alternatives of polyphenolic isolation following fermentation. Profitability was evaluated by comparing total revenue versus total costs through a break-even analysis of prices and production volumes.

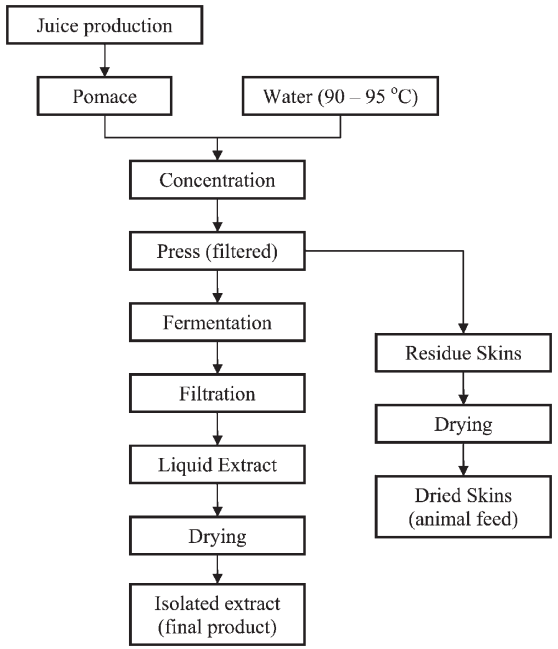

Fig. 1. Operation flow for a typical grape juice processor planning to process its byproduct to obtain an extract and dry residue skin $\left[\left(1.8 \times{ }^{\circ} \mathrm{C}\right)+32={ }^{\circ} \mathrm{F}\right]$.
Results were reported as minimum price (dollars per kilogram) and minimum volume (kilograms) needed to cover total annual costs, respectively. A ratio between production volume of extract and dried residue from the skins following fermentation was used for relevant calculations (124 and $11,309 \mathrm{~kg}$, respectively). In addition, a ratio between prices of the extract and the dried skins $(\$ 140 / \mathrm{kg}$ and $\$ 3.00 / \mathrm{kg}$, respectively) was applied, assuming that prices would fluctuate proportionally. Possible scenarios in the economical output were assessed by a sensitivity analysis conducted by modifying the production and price of the extract and the dried skins $( \pm 40 \%)$. Gross income and profit were displayed in the analysis for better illustration of the outcome. Results were reported in dollars per season. Finally, the economic return to the business was assessed over a period of 10 years by a cash flow analysis. Net present value (NPV) was calculated based on a discount rate (12\%), which was compared with a calculated internal rate of return (IRR). Inflation (3.43\%) was estimated by historical yearly inflation rates and consumer price indexes from 1980 through 2007 from the U.S. Bureau of Labor statistics. Depreciation of equipment was conducted by the straight line method with a $10 \%$ salvage value. A loan was calculated based on a fixed interest rate $(7.5 \%)$ and to be fully paid in 10 years. Results were expressed as dollars per season.

\section{Results and discussion}

The economics of the proposed spray drying and vacuum concentration technologies were evaluated and results are reported in dollars. For both operations (spray and vacuum concentration), the process was identical until the final step, where isolation of polyphenolics took place (drying).

SPRAY DRYING OPERATIONS. A used spray dryer with a capacity to remove $91 \mathrm{~kg}$ of water per hour was considered for the process. Details about the capital expenditure for equipment and construction required for this operation are listed in Table 3 . The initial investment was $\$ 120,640$, which included a spray dryer $(\$ 60,000)$, its installation fee $(\$ 24,000)$, and other required materials. Additional equipment necessary for this specific operation was not included because juice processors would typically own such equipment or materials already. As mentioned earlier in the assumptions, the new building construction was intended to be built with a bank loan, giving a total capital expenditure of $\$ 190,640$.

Total income for the incremental operation was calculated based on the seasonal production of extract and dried skins (124 and $11,309 \mathrm{~kg}$, respectively) and the price estimated and expected by an average muscadine grape producer for such extract and dried skins production. Furthermore, with knowledge of the equipment and material required by this

Table 3. Capital expenditure to initiate a process of extract and dried skin production from muscadine grape skins using spray drying as the isolation technique.

\begin{tabular}{|c|c|c|c|c|}
\hline Description & Unit & $\begin{array}{c}\text { Unit } \\
\text { cost }(\$)\end{array}$ & Quantity & $\begin{array}{c}\text { Total estimated } \\
\text { cost }(\$)\end{array}$ \\
\hline \multicolumn{5}{|c|}{ Equipment costs } \\
\hline Filter & Each & 25,000 & 1 & 25,000 \\
\hline Spray dryer & Each & 84,000 & 1 & 84,000 \\
\hline Pumps & Each & 1,200 & 2 & 2,400 \\
\hline \multirow[t]{2}{*}{ Containers (bins) } & Each & 220 & 42 & 9,240 \\
\hline & & & Subtotal & 120,640 \\
\hline \multirow{4}{*}{ New building ${ }^{\mathrm{x}}$} & & Constructi & & \\
\hline & Each & 70,000 & 1 & 70,000 \\
\hline & & & Subtotal & 70,000 \\
\hline & & & Grand total & 190,640 \\
\hline
\end{tabular}

${ }^{\mathrm{z}}$ Equipment listed in the table is applied directly to the expenditure of the operation. Other equipment needed for the operation is assumed to be already owned.

${ }^{y}$ Total construction cost for the new building includes wiring, electrical, and tubing installations.

${ }^{\mathrm{x}} \mathrm{New}$ building will be financed by a bank loan. 
operation, total costs were also calculated and used for further economic analyses. Once income and cost sources were determined, a production volume break-even point established the minimum production volume required to sustain the intended byproduct operation. From the break even equation, (revenues equal costs) Eq. [1] and the ratio between extract and dried skins production Eq. [2], I represented income from the extract $\left(\mathrm{I}_{\mathrm{E}}\right)$ and the residue skins $\left(\mathrm{I}_{\mathrm{R}}\right), \mathrm{C}$ represented costs, both fixed (FC) and variable from the two products $\left(\mathrm{VC}_{\mathrm{E}}\right.$ and $\left.\mathrm{VC}_{\mathrm{R}}\right)$, and $\mathrm{Q}$ represented the production of extract $\left(\mathrm{Q}_{\mathrm{E}}\right)$ and residue skins $\left(\mathrm{Q}_{\mathrm{R}}\right)$. After determination of costs of this potential operation, fixed costs $(\$ 25,162)$ and variables costs for extract and dried skins (\$79.6/unit and \$0.22/unit, respectively) were used to calculate the minimum quantity (kilograms) required to cover total operational costs. Results showed that $80.3 \mathrm{~kg}$ of extract and $7308 \mathrm{~kg}$ of dried skins were required to cover annual fixed and variable costs of an operation based on spray drying as an isolation method for polyphenolics. In addition, volume break-even point (Fig. 2 ) illustrated that by producing 80.3 $\mathrm{kg}$ of extract at $\$ 140 / \mathrm{kg}\left(\mathrm{p}_{\mathrm{E}}\right)$ and $7308 \mathrm{~kg}$ of dried skins at $\$ 3.00 / \mathrm{kg}$ $\left(p_{R}\right)$, total season cost was $\$ 33,168$, which was divided in fixed costs $(\$ 25,162)$ and variable costs (\$79.6/ $\mathrm{kg}$ of extract and $\$ 0.22 / \mathrm{kg}$ of dried skins). It is important to note that the results shown are rounded for better understanding, and final production volumes (kilograms) are a result of various calculations that are only rounded at the last step for accuracy.

$$
\begin{gathered}
I_{E}+I_{R}=F C+V C_{E}+V C_{R} \\
Q_{E}=0.011 Q_{R} \\
p_{E} \times Q_{E}+p_{R} \times Q_{R}=F C+V C_{E} \\
\times Q_{E}+V C_{R} \times Q_{R} \\
140 Q_{E}+3.0 Q_{R}=25,162+79.6 Q_{E} \\
+0.22 Q_{R} \\
140\left(0.011 Q_{R}\right)+3.0 Q_{R}=25,162 \\
+79.6\left(0.011 Q_{R}\right)+0.22 Q_{R} \\
4.54 Q_{R}-1.10 Q_{R}=25,162 \\
3.44 Q_{R}=25,162
\end{gathered}
$$

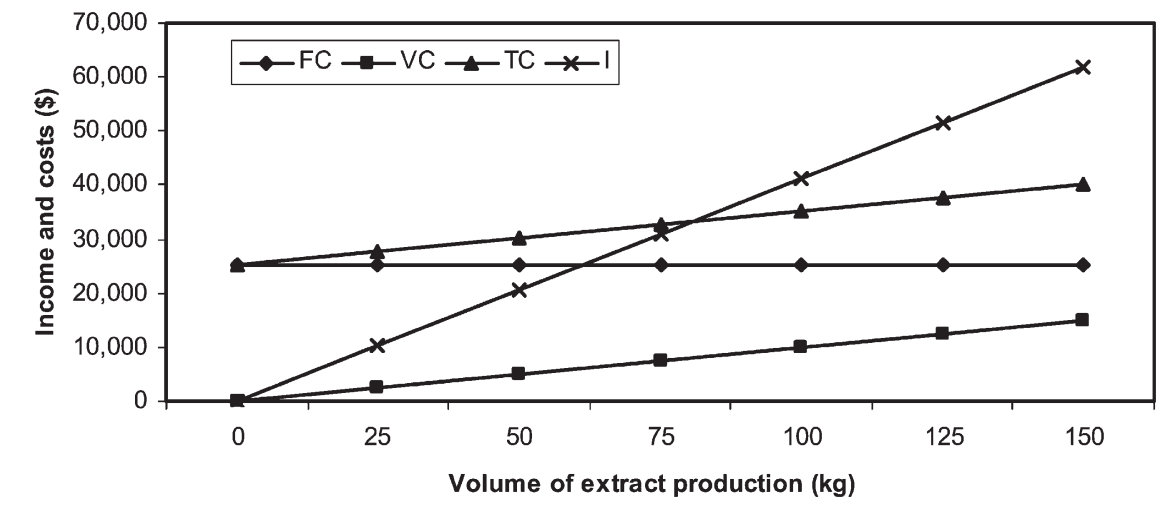

Fig. 2. Volume break-even point for an additional isolation procedure to obtain muscadine grape pomace extract and skin residue using a spray dryer $(\mathrm{FC}=$ fixed costs, $\mathrm{VC}=$ variable costs, $\mathrm{TC}=$ total costs, $\mathrm{I}=$ income). $\mathrm{X}$-axis only reflects the production of extract, while production of residue skins was not shown to avoid confusion $(1 \mathrm{~kg}=2.2046 \mathrm{lb})$.

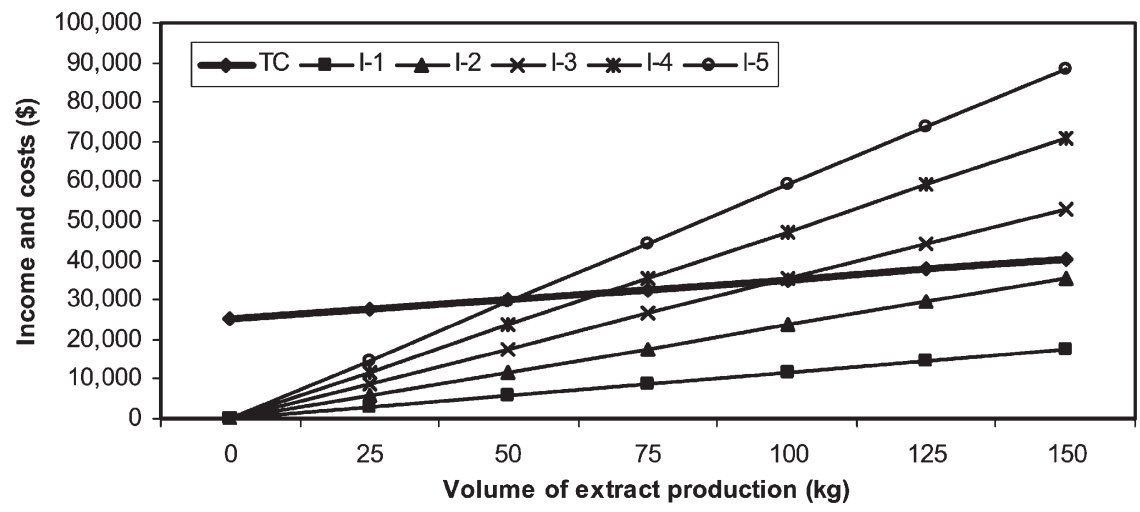

Fig. 3. Break-even point for an additional isolation procedure to obtain muscadine grape pomace extract and skin residue using a spray dryer as affected by price $(\mathrm{FC}=$ fixed costs, $\mathrm{I}=$ income). $\mathrm{X}$-axis only reflects the production of extract, while production of residue skins was not shown to avoid confusion. Prices ranged from $\$ 40 / \mathrm{kg}$ (I-1) to $\$ 200 / \mathrm{kg}$ (I-5) with increments of $\$ 40$ for the extract and proportionally from $\$ 0.86 / \mathrm{kg}(\mathrm{I}-1)$ to $\$ 4.29 / \mathrm{kg}(\mathrm{I}-5)$ with increments of $\$ 0.86$ for the residue skins $(1 \mathrm{~kg}=2.2046 \mathrm{lb}, \$ 1.00 / \mathrm{kg}=\$ 0.4536 / \mathrm{lb})$. 
reached $\$ 200 / \mathrm{kg}$ (extract) and \$4.29/ $\mathrm{kg}$ (dried skins), earnings were accomplished after only $50 \mathrm{~kg}$ of extract and $4500 \mathrm{~kg}$ of dried skins were produced. With such prices and the intended season production volume, gross income of almost $\$ 90,000$ was generated and profit increased up to $\$ 48,379$ in a single season.

$$
\begin{gathered}
I_{E}+I_{R}=F C+V C_{E}+V C_{R} \\
Q_{E}=0.011 Q_{R} \\
p_{E} \times Q_{E}+p_{R} \times Q_{R}=F C+V C_{E} \\
\times Q_{E}+V C_{R} \times Q_{R} \\
p_{E} \times\left(Q_{R} \times 0.011\right)+p_{R} \times Q_{R}=F C \\
+V C_{E} \times\left(Q_{R} \times 0.011\right) \\
+V C_{R} \times Q_{R} \\
Q_{R}\left(0.011 p_{E}+p_{R}\right) \\
=Q_{R}\left(F C / Q_{R}+0.011 V C_{E}+V C_{R}\right) \\
0.011 p_{E}+p_{R}=F C / Q_{R}+0.011 V C_{E}+V C_{R} \\
p_{E}=46.67 p_{R} \\
0.011\left(46.67 p_{R}\right)+p_{R}=25,162 / 11,310 \\
+0.011(79.6)+0.22 \\
p_{R}=\$ 2.19 / \mathrm{kg} \\
p_{E}=\$ 102.4 / \mathrm{kg}
\end{gathered}
$$

A sensitivity analysis for obtaining grape pomace extract and dried skin residue using a spray dryer was conducted (Table 4). Data suggested that a loss of more than $\$ 11,000$ could be anticipated if production and prices dropped $40 \%$. Losses were still registered when price or volume was reduced by $40 \%$. Under initial circumstances of a medium price range $(\$ 140 / \mathrm{kg}$ for the extract and $\$ 3.00 / \mathrm{kg}$ for the residue skins) and intermediate volumes (124 kg of extract and $11,309 \mathrm{~kg}$ of residue skins), a profit of almost $\$ 14,000$ in a season was registered. The remaining situa- tions also showed positive numbers. Therefore, this operation proved to be viable when the combination of production volumes and prices sur-

\begin{tabular}{|c|c|c|c|c|c|}
\hline \multirow[b]{2}{*}{$\begin{array}{l}\text { Production } \\
(\mathrm{kg})^{\mathrm{z}}\end{array}$} & \multirow[b]{2}{*}{ Ext/DSw } & \multirow[b]{2}{*}{$\mathrm{pExt} / \mathrm{pDS}^{\mathrm{v}}$} & \multicolumn{3}{|c|}{$\operatorname{Prices}(\$ / \mathbf{k g})^{\mathrm{z}}$} \\
\hline & & & $\frac{\text { Low }^{\mathrm{y}}}{100 / 2.14}$ & $\frac{\text { Medium }}{140 / 3.00}$ & $\frac{\text { High }^{\mathrm{x}}}{200 / 4.20}$ \\
\hline Low $^{y}$ & $88.8 / 8,078$ & $\begin{array}{l}\text { Sales }(\$)^{\mathrm{u}} \\
\text { Profit }(\$)^{\mathrm{t}}\end{array}$ & $\begin{array}{c}26,188 \\
(11,363)^{s}\end{array}$ & $\begin{array}{c}36,664 \\
(887)\end{array}$ & $\begin{array}{l}51,685 \\
14,133\end{array}$ \\
\hline Medium & $124 / 11,309$ & $\begin{array}{l}\text { Sales }(\$) \\
\text { Profit }(\$)\end{array}$ & $\begin{array}{c}36,664 \\
(887)\end{array}$ & $\begin{array}{l}51,329 \\
13,778\end{array}$ & $\begin{array}{l}72,358 \\
34,807\end{array}$ \\
\hline $\operatorname{High}^{x}$ & $174 / 15,833$ & $\begin{array}{l}\text { Sales }(\$) \\
\text { Profit }(\$)\end{array}$ & $\begin{array}{l}51,329 \\
13,778 \\
\end{array}$ & $\begin{array}{l}71,861 \\
34,310 \\
\end{array}$ & $\begin{array}{r}101,302 \\
63,750 \\
\end{array}$ \\
\hline 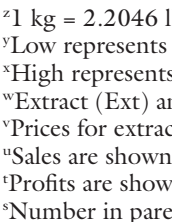 & $\begin{array}{l}\$ 1.00 / \mathrm{kg}=\$ 0.45 \\
\% \text { less of both med } \\
0 \% \text { more of both n } \\
\text { dried skin (DS) pr } \\
\text { pExt) and dried sk } \\
\text { r all nine different } \\
\text { for all nine differen } \\
\text { hesis indicates prof }\end{array}$ & $\begin{array}{l}\text { lb } \\
\text { a prices and volur } \\
\text { um prices and vo } \\
\text { ction are displaye } \\
\text { (pDS) are display } \\
\text { posed scenarios. } \\
\text { pposed scenarios } \\
\text { ss. }\end{array}$ & $\begin{array}{l}\text { ies. } \\
\text { ertically in the } \\
\text { horizontally in }\end{array}$ & le. & \\
\hline
\end{tabular}
passed low-low and low-medium combinations.

The economic return was

\begin{tabular}{|c|c|c|c|c|c|c|c|c|c|c|c|}
\hline \multirow{2}{*}{ Periods (years) } & \multicolumn{11}{|c|}{ Monetary values (\$) } \\
\hline & 0 & 1 & 2 & 3 & 4 & 5 & 6 & 7 & 8 & 9 & 10 \\
\hline Investment & \multicolumn{11}{|l|}{120,640} \\
\hline Extract & & 17,401 & 17,998 & 18,615 & 19,254 & 19,914 & 20,597 & 21,304 & 22,035 & 22,790 & 23,572 \\
\hline Residue & & 33,928 & 35,092 & 36,296 & 37,540 & 38,828 & 40,160 & 41,537 & 42,962 & 44,436 & 45,960 \\
\hline \multicolumn{12}{|l|}{ Expenses } \\
\hline General costs & & 1,753 & 1,813 & 1,874 & 1,938 & 2,004 & 2,072 & 2,142 & 2,215 & 2,291 & 2,369 \\
\hline Depreciation & & 18,303 & 18,303 & 18,303 & 18,303 & 18,303 & 4,424 & 4,424 & 4,424 & 4,424 & 4,424 \\
\hline Interest $(7.5 \%)$ & & 998 & 998 & 893 & 788 & 683 & 578 & 473 & 368 & 263 & 158 \\
\hline Gross income & & 19,767 & 21,215 & 22,710 & 24,253 & 25,845 & 41,367 & 43,064 & 44,815 & 46,622 & 48,488 \\
\hline $\operatorname{Tax}(20 \%)$ & & 3,953 & 4,243 & 4,542 & 4,851 & 5,169 & 8,273 & 8,613 & 8,963 & 9,324 & 9,698 \\
\hline Net income & & 27,589 & 28,643 & 29,734 & 30,863 & 39,742 & 30,465 & 31,717 & 33,013 & 34,354 & 35,742 \\
\hline Net present value & & 177,808 & & & & & & & & & \\
\hline Internal rate of ret & $\operatorname{urn}(\%)$ & 22.2 & & & & & & & & & \\
\hline
\end{tabular}
assessed over a 10-year period of operation by a cash flow analysis (Table 5). With a net present value (NPV) of $\$ 177,808$ and an investment of $\$ 120,640$, the operation returned the investment in less than 6 years and generated almost $\$ 60,000$ of earnings in 10 years. This capital produced was the first sign that

Table 4. Sensitivity analysis for a process to obtain extract and dried skins from muscadine grape skins using spray drying as the isolation technique.

Table 5. Cash flow analysis for a process to obtain extract and dried skins from muscadine grape skins using spray drying as the isolation technique. 
demonstrated the productivity of this additional operation. The internal rate of return (IRR) was another parameter to assess effectiveness on an operation in the cash flow analysis. With average annual income of more than $\$ 30,000$, the IRR (22.2\%) was more than $10 \%$ higher than the rate used for the NPV calculation (12\%), thus showing positive results for this additional operation for the muscadine grape industry.

VACUUM CONCENTRATION OPERATIONS. The vacuum dryer cited in this situation had a capacity to remove $300 \mathrm{~kg}$ of water per hour. Details about the capital expenditure for equipment and construction required for this operation are listed in Table 6. Total investments $(\$ 256,640)$ included the purchase of a vacuum dryer $(\$ 107,143)$, its installation fee $(\$ 42,857)$, construction costs $(\$ 70,000)$, and other required materials. Additional equipment necessary for this specific operation was not included because juice processors would typically own the necessary equipment already.

Once revenue and cost sources were established, production and price break-even analyses were used to determine minimum production required and minimum prices at constant production volumes to sustain the intended by-product operation. The break even equation Eq. [1], the proportion between extract and residue skins productions Eq. [2], and the proportion between prices Eq. [3] were used for this analysis. Calculations indicated that to cover annual fixed and variable costs of the operation, $118 \mathrm{~kg}$ of extract and 10,758 kg of dried skins should be produced at $\$ 140 / \mathrm{kg}$ and $\$ 3.00 / \mathrm{kg}$, respectively. These calculations were illustrated by showing the point at which the gross income generated covered season costs of $\$ 48,828$ (Fig. 4 ). The total cost is divided in fixed $(\$ 37,419)$ and variable $(\$ 76.5 / \mathrm{kg}$ of extract and $\$ 0.22 / \mathrm{kg}$ of dried skins) costs. When using an evaporator of such specifications, the demand for volume of both products was high due to the elevated cost of the equipment (investment). According to these calculations and the production levels used for extract and skin residue (124 and $11,309 \mathrm{~kg}$, respectively), only $6 \mathrm{~kg}$ of extract and $55 \mathrm{l} \mathrm{kg}$ of dried skins represented earnings in the season.
Table 6. Capital expenditure to initiate a process of extract and dried skin production from muscadine grape skins using vacuum concentration as the isolation technique.

\begin{tabular}{|c|c|c|c|c|}
\hline Description & Unit & $\begin{array}{l}\text { Unit cost } \\
(\$)\end{array}$ & Quantity & $\begin{array}{c}\text { Total estimated } \\
\text { cost }(\$)\end{array}$ \\
\hline \multicolumn{5}{|c|}{ Equipment costs } \\
\hline Filter & Each & 25,000 & 1 & 25,000 \\
\hline Vacuum dryer & Each & 150,000 & 1 & 150,000 \\
\hline Pumps & Each & 1,200 & 2 & 2,400 \\
\hline \multirow[t]{2}{*}{ Containers (bins) } & Each & 220 & 42 & 9,240 \\
\hline & & Subtotal & & 186,640 \\
\hline \multicolumn{5}{|c|}{ Construction costs } \\
\hline \multirow[t]{3}{*}{ New building ${ }^{x}$} & Each & 70,000 & 1 & 70,000 \\
\hline & & Subtotal & & 70,000 \\
\hline & & Grand total & & 256,640 \\
\hline
\end{tabular}

${ }^{\mathrm{z}}$ Equipment listed in the table is applied directly to the expenditure of the operation. Other equipment needed for the operation is assumed to be already owned.

yTotal construction cost for the new building includes wiring, electrical, and tubing installations.

${ }^{\mathrm{x}} \mathrm{New}$ building will be constructed with a bank loan.

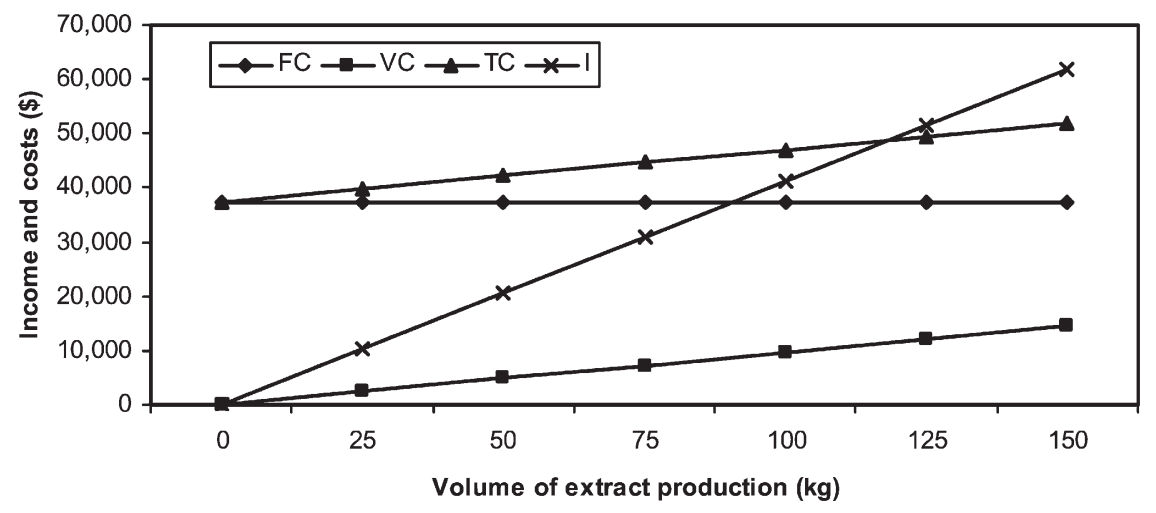

Fig. 4. Volume break-even point for an additional isolation procedure to obtain muscadine grape pomace extract and skin residue using a vacuum dryer ( $\mathrm{FC}=$ fixed costs, $\mathrm{VC}=$ variable costs, $\mathrm{TC}=$ total costs, $\mathrm{I}=$ income $). \mathrm{X}$-axis only reflects the production of extract, while production of residue skins was not shown to avoid confusion $(1 \mathrm{~kg}=2.2046 \mathrm{lb})$.

$$
\begin{gathered}
I_{E}+I_{R}=F C+V C_{E}+V C_{R} \\
Q_{E}=0.011 Q_{R} \\
p_{E} \times Q_{E}+p_{R} \times Q_{R}=F C+V C_{E} \\
\times Q_{E}+V C_{R} \times Q_{R} \\
140 Q_{E}+3.0 Q_{R}=37,419+76.5 Q_{E} \\
+0.22 Q_{R} \\
140\left(0.011 Q_{R}\right)+3.0 Q_{R}=37,419 \\
+76.5\left(0.011 Q_{R}\right)+0.22 Q_{R} \\
4.54 Q_{R}-1.06 Q_{R}=37,419 \\
3.48 Q_{R}=37,419 \\
Q_{R}=37,419 / 3.48 \\
Q_{R}=10,758.22 \mathrm{~kg}
\end{gathered}
$$

Total annual costs were covered when prices of extract (124 kg) and dried skins $(11,309 \mathrm{~kg})$ surpassed $\$ 135 / \mathrm{kg}$ and $\$ 2.89 / \mathrm{kg}$, respectively. Five scenarios in which prices varied as described previously illustrated the impact of price changes in the overall operation (Fig. 5). Unlike the analysis with spray drying, profit with a production less than $150 \mathrm{~kg}$ of extract and over $13,500 \mathrm{~kg}$ of dried skins required a price of at least $\$ 120 / \mathrm{kg}$ (extract) and $\$ 2.57 / \mathrm{kg}$ (dried skins). At such prices, a profit of only $\$ 1203$ was accomplished. In contrast, season earnings of $\$ 36,600$ were reached when $150 \mathrm{~kg}$ of extract and 13,500 $\mathrm{kg}$ of dried skins were produced at the highest prices analyzed $(\$ 200 / \mathrm{kg}$ and $\$ 4.29 / \mathrm{kg}$, respectively). 


$$
\begin{gathered}
I_{E}+I_{R}=F C+V C_{E}+V C_{R} \\
Q_{E}=0.011 Q_{R} \\
I_{E}+I_{R}=F C+V C_{E}+V C_{R} \\
p_{E} \times Q_{E}+p_{R} \times Q_{R}=F C+V C_{E} \\
\times Q_{E}+V C_{R} \times Q_{R} \\
p_{E} \times\left(Q_{R} \times 0.011\right)+p_{R} \times Q_{R}=F C \\
+V C_{E} \times\left(Q_{R} \times 0.011\right) \\
+V C_{R} \times Q_{R} \\
Q_{R}\left(0.011 p_{E}+p_{R}\right) \\
=Q_{R}\left(F C / Q_{R}+0.011 V C_{E}+V C_{R}\right) \\
0.011 p_{E}+p_{R}=F C / Q_{R}+0.011 V C_{E}+V C_{R} \\
p_{E}=46.67 p_{R} \\
0.011\left(46.67 p_{R}\right)+p_{R}=37,419 / 11,310 \\
+0.011(76.5)+0.11 \\
p_{R}=\$ 2.89 / \mathrm{kg} \\
p_{E}=\$ 135 / \mathrm{kg}
\end{gathered}
$$

A sensitivity analysis for obtaining grape pomace extract and dried skin residue using a vacuum evaporator was conducted (Table 7) and there were losses in the low-low and medium-low combinations of production and prices. The remaining situations showed positive numbers, but only the medium-high and highhigh combinations showed profits over $\$ 22,000$. For a cash flow analysis, vacuum concentration resulted in a NPV of $\$ 188,627$. When investment was subtracted from the NPV, a profit of less than $\$ 2000$ was accomplished due to the expensive characteristics of the equipment quoted (Table 8). Although NPV calculated for an operation with vacuum concentration was higher than with spray drying, most of the money earned in a 10-year operation period was used to pay the initial investment, which resulted in a low $\operatorname{IRR}(12.3 \%)$.

Although the price of the evaporator was high, profit was reached in

\begin{tabular}{|c|c|c|c|c|c|}
\hline \multirow[b]{2}{*}{$\begin{array}{l}\text { Production } \\
(\mathrm{kg})^{\mathrm{z}}\end{array}$} & \multirow[b]{2}{*}{$\mathrm{Ext} / \mathrm{DS}^{\mathrm{w}}$} & \multirow[b]{2}{*}{$\mathrm{pExt} / \mathrm{pDS}^{\mathrm{v}}$} & \multicolumn{3}{|c|}{ Prices $(\$ / \mathrm{kg})^{\mathrm{z}}$} \\
\hline & & & $\frac{\text { Low }^{\mathrm{y}}}{100 / 2.14}$ & $\frac{\text { Medium }}{140 / 3.00}$ & $\frac{\text { High }^{\mathrm{x}}}{200 / 4.20}$ \\
\hline Low $^{y}$ & $88.8 / 8,078$ & $\begin{array}{l}\text { Sales }(\$)^{\mathrm{u}} \\
\text { Profit }(\$)^{\mathrm{t}}\end{array}$ & $\begin{array}{c}26,188 \\
(23,224)^{\mathrm{s}}\end{array}$ & $\begin{array}{c}36,664 \\
(12,749)\end{array}$ & $\begin{array}{r}51,685 \\
2,272\end{array}$ \\
\hline Medium & $124 / 11,309$ & $\begin{array}{l}\text { Sales }(\$) \\
\text { Profit }(\$)\end{array}$ & $\begin{array}{c}36,664 \\
(12,749)\end{array}$ & $\begin{array}{r}51,329 \\
1,917\end{array}$ & $\begin{array}{l}72,358 \\
22,946\end{array}$ \\
\hline $\operatorname{High}^{x}$ & $174 / 15,833$ & $\begin{array}{l}\text { Sales }(\$) \\
\text { Profit }(\$)\end{array}$ & $\begin{array}{r}51,329 \\
1,917\end{array}$ & $\begin{array}{l}71,861 \\
22,449\end{array}$ & $\begin{array}{r}101,302 \\
51,889\end{array}$ \\
\hline
\end{tabular}
the first year and covered the season's costs. Moreover, if the process is successful and projected to grow, the evaporator analyzed in this scenario would have enough capacity to

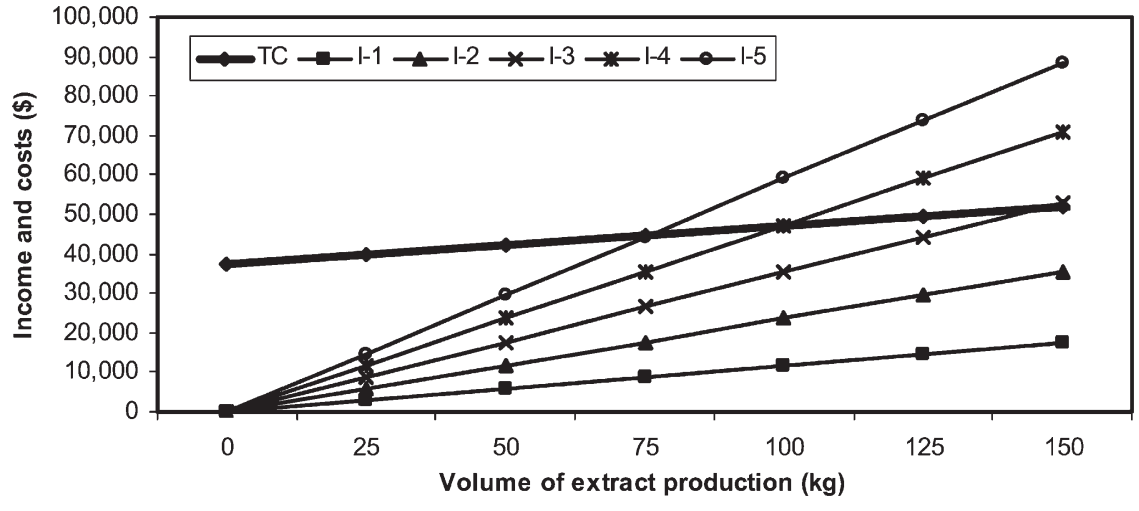

Fig. 5. Break-even point for an additional isolation procedure to obtain muscadine grape pomace extract and skin residue using a vacuum dryer as affected by price $(\mathrm{FC}=$ fixed costs, $\mathrm{I}=$ income $) . \mathrm{X}$-axis only reflects the production of extract, while production of residue skins was not shown to avoid confusion. Prices ranged from $\$ 40 / \mathrm{kg}(\mathrm{I}-\mathrm{-})$ to $\$ 200 / \mathrm{kg}(\mathrm{I}-5)$ with increments of $\$ 40$ for the extract and proportionally from $\$ 0.86 / \mathrm{kg}$ (I-1) to $\$ 4.29 / \mathrm{kg}(\mathrm{I}-5)$ with increments of $\$ 0.86$ for the residue skins $(1 \mathrm{~kg}=2.2046 \mathrm{lb}, \$ 1.00 / \mathrm{kg}=\$ 0.4536 / 1 \mathrm{~b})$.

Table 7. Sensitivity analysis for a process to obtain extract and dried skins from muscadine grape skins using vacuum concentration as the isolation technique.

${ }^{\mathrm{z}} \mathrm{l} \mathrm{kg}=2.2046 \mathrm{lb}, \$ 1.00 / \mathrm{kg}=\$ 0.4536 / \mathrm{lb}$

y Low represents $40 \%$ less of both medium prices and volumes.

${ }^{\mathrm{x}}$ High represents $40 \%$ more of both medium prices and volumes.

wExtract (Ext) and dried skin (DS) production are displayed vertically in the table.

"Prices for extract (pExt) and dried skins (pDS) are displayed horizontally in the table.

"Sales are shown for all nine different supposed scenarios.

tProfits are shown for all nine different supposed scenarios.

${ }^{\mathrm{s}}$ Number in parenthesis indicate profit loss.

support such growth while the spray dryer, used in the previous analysis, operated more than 10 h daily compared with the 4-h operation of the evaporator. Therefore, if vacuum concentration is implemented, it has room for growth without severe changes in the process line. In addition, higher yields could be obtained if processes were optimized to extract more polyphenolics from muscadine grape pomace, generating additional profit for selling more extract at $\$ 140 / \mathrm{kg}$ than dry skins at $\$ 3.00 / \mathrm{kg}$.

\section{Conclusions}

Aerobic fermentation following a simple concentration step was an inexpensive way to obtain polyphenolics from muscadine grape skins because most of the investment was focused in the latter procedure (isolation). Results from two isolation techniques of polyphenolics from muscadine grape skins suggested that this additional operation can be suitable and profitable for a typical muscadine producer. Further investigation is needed to optimize the polyphenolic concentration procedure before fermentation to increment the extract produced and, consequently, increase profit. Using initial production conditions (124 kg at $\$ 140 / \mathrm{kg}$ and $11,309 \mathrm{~kg}$ at $\$ 3.00 / \mathrm{kg}$, respectively), the profit generated from spray drying was higher than vacuum concentration. In contrast, the vacuum evaporator used as an example for this situation had three times the capacity of the spray dryer, thus only the 
Table 8. Cash flow analysis for a process to obtain extract and dried skins from muscadine grape skins using vacuum concentration as the isolation technique.

\begin{tabular}{|c|c|c|c|c|c|c|c|c|c|c|c|}
\hline \multirow[b]{2}{*}{ Periods (years) } & \multicolumn{11}{|c|}{ Monetary values (\$) } \\
\hline & 0 & 1 & 2 & 3 & 4 & 5 & 6 & 7 & 8 & 9 & 10 \\
\hline Investment & 186,640 & & & & & & & & & & \\
\hline Extract & & 17,401 & 17,998 & 18,615 & 19,254 & 19,914 & 20,597 & 21,304 & 22,035 & 22,790 & 23,572 \\
\hline Residue & & 33,928 & 35,092 & 36,296 & 37,540 & 38,828 & 40,160 & 41,537 & 42,962 & 44,436 & 45,960 \\
\hline \multicolumn{12}{|l|}{ Expenses } \\
\hline General costs & & 1,357 & 1,403 & 1,451 & 1,500 & 1,551 & 1,604 & 1,659 & 1,715 & 1,773 & 1,834 \\
\hline Depreciation & & 26,789 & 26,789 & 26,789 & 26,789 & 26,789 & 4,424 & 4,424 & 4,424 & 4,424 & 4,424 \\
\hline Interest $(7.5 \%)$ & & 998 & 998 & 893 & 788 & 683 & 578 & 473 & 368 & 263 & 158 \\
\hline Gross income & & 11,677 & 13,139 & 14,648 & 16,205 & 17,812 & 41,836 & 43,548 & 45,315 & 47,140 & 49,023 \\
\hline Tax $(20 \%)$ & & 2,335 & 2,628 & 2,930 & 3,241 & 3,562 & 8,367 & 8,710 & 9,063 & 9,428 & 9,805 \\
\hline Net income & & 29,603 & 30,668 & 31,770 & 32,910 & 46,516 & 30,840 & 32,105 & 33,414 & 34,768 & 36,170 \\
\hline Net present value & & 188,627 & & & & & & & & & \\
\hline Internal rate of retu & $\operatorname{lnn}(\%)$ & 12.3 & & & & & & & & & \\
\hline
\end{tabular}

evaporator could support a growth in extract production if the volume processed is increased significantly. Another advantage of vacuum concentration for a muscadine grape processor is the versatility to obtain powder and/or concentrate products, depending on the purchaser requirements, whereas spray drying would produce only a powder, limiting the market for the isolated extract. Although vacuum concentration showed the highest investment on this analysis, there are many other factors that make spray drying technology expensive to adjust, especially for a typical muscadine grape processor. This study illustrated various assumptions that could be changed to recalculate and readjust the investment and costs of any processor. It is important to note that by-products from wineries could represent an additional source of pomace for the extraction of polyphenolics in addition to the by-product of juice operations. Due to limited information regarding equipment, this study only contained general information for engineering and equipment specifications; thus, many other specifications can be added to predict economic information more accurately. Furthermore, this process could be adjusted and implemented for byproducts from various fruit and vegetables sources to estimate the increase in profit of their industries.

\section{Literature cited}

Bonilla, F., M. Mayen, J. Merida, and M. Medina. 1999. Extraction of phenolic compounds from red grape marc for use as food lipid antioxidants. Food Chem. 66:209-215.

Cardona, J.A. 2007. Chemical and economical analysis of a value added product from muscadine grape pomace. Univ. Florida, Gainesville, M.S. thesis.

Ector, B.J. 2001. Compositional and nutritional characteristics, p. 341-367. In: F.M. Basiouny and D.G. Himelrick (eds.). Muscadine grapes. ASHS Press, Alexandria, VA.

Klopotek, Y., K. Otto, and V. Bohm. 2005. Processing strawberries to different products alters contents of vitamin C, total phenolics, total anthocyanins and antioxidant capacity. J. Agr. Food Chem. 53:5640-5646.

Meyer, A.S., K.I. Suhr, P. Nielsen, and F. Holm. 2002. Natural food preservatives, p. 124-176. In: T. Ohlsson and N. Bengtsson (eds.). Minimal processing technologies in the food industry. CRC Press, Boca Raton, FL.

Milo, L. 2005. Nutraceuticals and functional foods. Food Technol. 59:65-67.

Monagas, M., B. Hernández-Ledesma, C. Gómez-Cordovés, and B. Bartolomé.
2006. Commercial dietary ingredients from Vitis vinifera L. leaves and grape skins: Antioxidant and chemical characterization. J. Agr. Food Chem. 54:319327.

Morris, J.R. and P.L. Brady. 2004. The muscadine experience: Adding value to enhance profits. Arkansas Agr. Expt. Sta., Inst. Food Sci. Eng., Univ. Arkansas, Fayetteville.

Moure, A., J.M. Cruz, D. Franco, J.M. Domínguez, J. Sineiro, H. Domínguez, M.J. Núñez, and J.C. Parajó. 2001. Natural antioxidants from residual sources. Food Chem. 72:145-171.

Olien, W.C. and C.P. Hegwood. 1990. Muscadine: A classic southeastern fruit. HortScience 25:726-727.

Pastrana-Bonilla, E., C. Akoh, S. Sellapan, and G. Krewer. 2003. Phenolic content and antioxidant capacity of muscadine grapes. J. Agr. Food Chem. 51:54975503.

Phillips, R.D. 2006. Pilot-scale, precommercial production of nutraceuticals from Georgia commodities, p. 10. In: Fiscal year 2005-2006 report to industry. Georgia's traditional industries program for food processing. $15 \mathrm{Dec}$. 2008. <http://foodpac.gatech.edu/ publications.html>.

Poling, E.B. 1996. Muscadine grapes in the home garden. Dept. Hort. Sci., North Carolina Coop. Ext. Serv., North Carolina State Univ., Raleigh. 


\section{Research Reports}

Ruel, J. and A. Walker. 2006. Resistance to pierce's disease in Muscadinia rotundifolia and other native grape species. Amer. J. Enol. Viticult. 57:158-166.

Saftley, C.D., E.B. Poling, M.K. Wohlgenant, O. Sydorovych, and R.F. Williams. 2004. Producing and marketing straw- berries for direct market operations. HortTechnology 14:124-135.

Saftley, C.D., O. Boldea, and G.E. Fernandez. 2006. Estimated costs of producing, harvesting, and marketing blackberries in the southeastern United States. HortTechnology 16:109-117.
Visioli, F., A. Romani, N. Mulinacci, S. Zarini, D. Conte, F.F. Vincieri, and C. Galli. 1999. Antioxidant and other biological activities of olive mill waste waters. J. Agr. Food Chem. 47:33973401 . 